\title{
Disynaptic Amplification of Metabotropic Glutamate Receptor 1 Responses in the Olfactory Bulb
}

\author{
Didier De Saint Jan and Gary L. Westbrook \\ Vollum Institute, Oregon Health \& Science University, Portland, Oregon 97239
}

\begin{abstract}
Sensory systems often respond to rapid stimuli with high frequency and fidelity, as perhaps best exemplified in the auditory system. Fast synaptic responses are fundamental requirements to achieve this task. The importance of speed is less clear in the olfactory system. Moreover, olfactory bulb output mitral cells respond to a single stimulation of the sensory afferents with unusually long EPSPs, lasting several seconds. We examined the temporal characteristics, developmental regulation, and the mechanism generating these responses in mouse olfactory bulb slices. The slow EPSP appeared at postnatal days 10-11 and was mediated by metabotropic glutamate receptor 1 (mGluR1) and NMDA receptors. mGluR1 contribution was unexpected because its activation usually requires strong, high-frequency stimulation of inputs. However, dendritic release of glutamate from the intraglomerular network caused spillover-mediated recurrent activation of metabotropic glutamate receptors. We suggest that persistent responses in mitral cells amplify the incoming sensory information and, along with asynchronous inputs, drive odor-evoked slow temporal activity in the bulb.
\end{abstract}

Key words: mGluR; olfactory bulb; mitral cell; glutamate spillover; glomerulus; synaptic transmission

\section{Introduction}

Dynamic spatiotemporal activity in the olfactory bulb undoubtedly contributes to olfactory perception. Odors evoke a topographical map of glomerular activity in the bulb that provides the basic spatial code for odor identification (Axel, 2005; Buck, 2005). Mitral cells in the bulb or their analog in invertebrates (projection neurons) respond to odors with sustained trains or bursts of action potentials (Laurent et al., 1996; Charpak et al., 2001; Luo and Katz, 2001; Wilson et al., 2004). This firing pattern across a population of cells evolves over time in an odor-specific manner, thus forming a temporal signature that can also contribute to odor identification (Friedrich and Laurent, 2001; Laurent et al., 2001; Wilson et al. 2004). Postsynaptic mechanisms such as lateral inhibition mediated by interneurons (MacLeod and Laurent, 1996; Schoppa et al., 1998; Lagier et al., 2004) or intraglomerular excitatory interactions (Schoppa and Westbrook, 2001, 2002; Urban and Sakmann, 2002; Christie and Westbrook, 2006) modulate mitral cell responses. This postsynaptic machinery depends critically on the time course of mitral cell excitation driven by afferent inputs.

Single electrical stimulation of these sensory afferents evokes a surprisingly long-lasting depolarization in mitral cells (Nowycky et al., 1981; Chen and Shepherd, 1997; Carlson et al., 2000; Schoppa and Westbrook, 2001). Although the olfactory nerve $(\mathrm{ON})$-evoked mitral cell depolarization is usually abolished by

Received June 8, 2006; revised 0ct. 20, 2006; accepted Nov. 27, 2006.

This work was supported by Human Frontier Science Program Grant LT00283/2002-C (D.D.S.J.) and National Institutes of Health Grant NS 26494 (G.L.W.). We thank Aesoon Bensen for technical assistance and members of the Westbrook laboratory for support and suggestions during this project.

Correspondence should be addressed to Dr. Didier De Saint Jan, Institut National de la Santé et de la Recherche Médicale U603, 45 rue des Saints Pères, 75006 Paris, France. E-mail: didier.desaintjan@univ-paris5.fr. DOI:10.1523/JNEUROSCI.2439-06.2007

Copyright $\odot 2007$ Society for Neuroscience $\quad$ 0270-6474/07/270132-09\$15.00/0
AMPA and NMDA receptor antagonists (Chen and Shepherd, 1997; Carlson et al., 2000; Schoppa and Westbrook, 2001; De Saint Jan and Westbrook, 2005), the duration of the EPSP far exceeds even the slow NMDA receptor-mediated EPSP in most pathways, suggesting that another component is likely. The metabotropic glutamate receptor 1 (mGluR1) is expressed in mitral cell postsynaptic dendrites (van den Pol, 1995) and can affect mitral cell excitability (Schoppa and Westbrook, 2001; Heinbockel et al., 2004). However, mGluR1-mediated EPSPs/EPSCs have only been reported after high-frequency stimulation of presynaptic neurons or when glutamate transporters are blocked (Batchelor and Garthwaite, 1997; Brasnjo and Otis, 2001; Dzubay and Otis, 2002; Huang et al., 2004; De Saint Jan and Westbrook, 2005; Ennis et al., 2006; Yuan and Knopfel, 2006). Such protocols presumably are required because they facilitate glutamate spillover onto perisynaptic loci where mGluRs are generally expressed (Baude et al., 1993).

We used whole-cell patch-clamp recordings in mouse olfactory bulb slices to elucidate the mechanism generating longlasting mitral cell EPSPs. We show that mGluR1s can be robustly activated after a single stimulation of the sensory afferents and mediated, along with NMDA receptors, the long-lasting synaptic excitation of mitral cells. Activation of mGluR1 and NMDA receptor was initiated by glutamate released from afferent nerve terminals but required secondary release from the intraglomerular network of mitral and tufted cell dendrites. This mechanism allows for glomerular-specific and persistent increases in excitability in response to asynchronous or periodic afferent input.

\section{Materials and Methods}

We prepared horizontal olfactory bulb slices from wild-type, connexin $36^{-1-}\left(\mathrm{Cx} 36^{-1-}\right)$ (Hormuzdi et al., 2001), and mGluR1 ${ }^{-1-}$ (Conquet et al., 1994) mice following a protocol approved by the Animal Care 


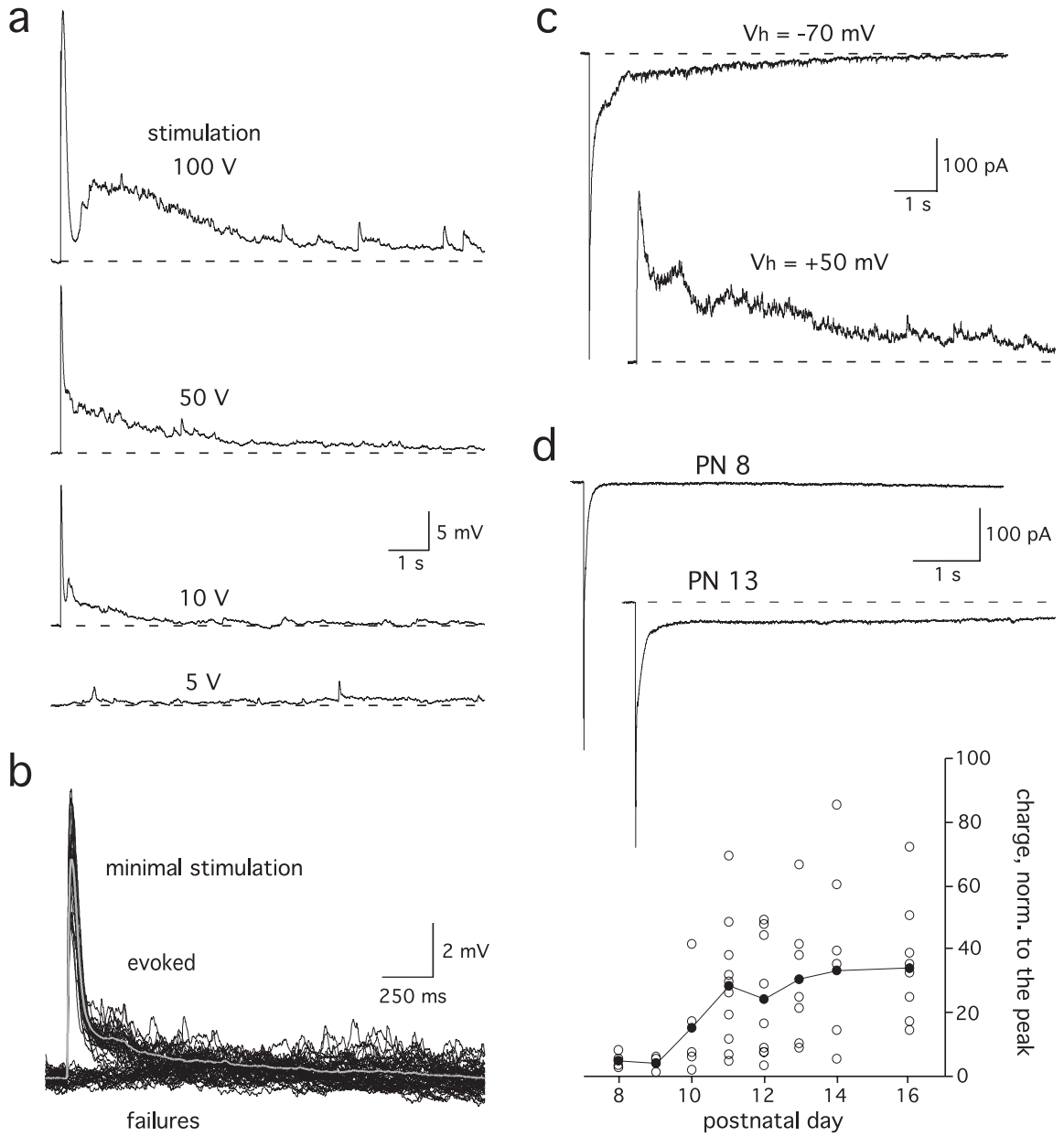

Figure 1. Single ON stimulation evoked long-lasting synaptic responses in mitral cells. $\boldsymbol{a}$, Mitral cell EPSPs evoked in an olfactory bulb slice by a single stimulation of the $0 \mathrm{~N}$ layer $(1$ shock, $100 \mu \mathrm{s})$ at different intensities. Each trace is an average of five episodes. $\boldsymbol{b}$, For the same cell as shown in $a$, mitral cell responses were all or none at a stimulation intensity that produced $\sim 50 \%$ responses and $50 \%$ failures (9V stimulation in this example). The average of 49EPSPs (gray trace) is superimposed. c, In voltage-clamp recordings, the EPSCs (top, -70 $\mathrm{mV}$ ) reversed polarity at a positive holding potential (bottom, $+50 \mathrm{mV}$ ). $\boldsymbol{d}$, The duration of the mitral cell EPSCs increased markedly after postnatal day (PN) 10. The intensity of the stimulation was set to evoke responses with peak amplitudes of 300-700 pA. Bottom, The integral of the EPSC was normalized to the peak amplitude and plotted as a function of age.

and Use Committee of the Oregon Health \& Science University. Wildtype controls included $\mathrm{Cx} 36^{+/+}$and mGluR $1^{+/+}$littermates as well as unrelated C57BL/6 mice. As described previously (Schoppa et al., 1998), mice were anesthetized with halothane and decapitated. Bulbs were removed, and slices (290-350 $\mu \mathrm{m}$ ) were cut in ice-cold oxygenated solution containing the following (in $\mathrm{mm}$ ): $83 \mathrm{NaCl}, 26.2 \mathrm{NaHCO}_{3}, 1$ $\mathrm{NaH}_{2} \mathrm{PO}_{4}, 2.5 \mathrm{KCl}, 3.3 \mathrm{MgSO}_{4}, 0.5 \mathrm{CaCl}_{2}, 70$ sucrose, and 22 dextrose, pH 7.3 (osmolarity adjusted to $290 \mathrm{mOsm}$ ). Slices were incubated for $30-40 \mathrm{~min}$ at $37^{\circ} \mathrm{C}$ and then at room temperature until use.

For electrophysiology, slices were transferred to an external solution (in mM: $125 \mathrm{NaCl}, 25 \mathrm{NaHCO}_{3}, 2.5 \mathrm{KCl}, 1.25 \mathrm{NaH}_{2} \mathrm{PO}_{4}, 1 \mathrm{MgCl}_{2}, 2$ $\mathrm{CaCl}_{2}$ and 25 dextrose) and visualized with an upright microscope (BX51WI; Olympus, Tokyo, Japan) using differential interference contrast optics. Patch pipettes $(\sim 4 \mathrm{M} \Omega)$ for whole-cell current-clamp recording were filled with a solution containing the following (in $\mathrm{mM}$ ): 135 K-gluconate, $2 \mathrm{MgCl}_{2}, 2 \mathrm{CaCl}_{2}, 1 \mathrm{EGTA}, 4 \mathrm{Na}$-ATP, $0.5 \mathrm{Na}$-GTP, and 10 HEPES, pH 7.3 (osmolarity, $\sim 270 \mathrm{mOsm}$ ). For voltage-clamp recordings, we used an internal solution in which $120 \mathrm{~mm}$ Cs- $\mathrm{MeSO}_{4}, 20 \mathrm{~mm}$ tetraethylammonium-Cl, and $5 \mathrm{~mm}$ 4-aminopyridine replaced K-gluconate. Alexa-Fluor $488(10 \mu \mathrm{M})$ was routinely added in the internal solution to visualize mitral cell dendrites under fluorescent illumination. Experiments were performed at $33-36^{\circ} \mathrm{C}$.

Recordings were made with a multiclamp 700A amplifier (Molecular Devices, Foster City, CA), filtered at $2 \mathrm{~Hz}$, and digitized at $5-10 \mathrm{kHz}$ using
Axograph 4.9 (Molecular Devices). For current-clamp recordings, a negative current was injected to maintain mitral cells below action potential threshold (approximately -70 $\mathrm{mV}$ ). We used the bridge balance function of the amplifier to compensate access resistance. Mitral cells that projected to the same glomerulus were identified visually with Alexa 488 and by the presence of electrical coupling (Schoppa and Westbrook, 2002). The axons of olfactory sensory neurons were stimulated using a patch pipette filled with an external solution and positioned in the fiber layer entering the glomerulus to which the test mitral cell projected. The electrical stimulus (100 $\mu$ s; intensity, 1-100 V) was triggered using an isolated stimulator (Digitimer, Hertfordshire, UK). We used Student's $t$ tests (two-tailed) for statistical comparison. We expressed the results as mean \pm SEM.

Drugs 6-nitro-7-sulfamoylbenzo[f]quinoxaline2,3-dione (NBQX), (+)-2-methyl-4-carboxyphenylglycine (LY367385), DL-2-amino-5phosphonovaleric acid (AP-5), 7-(hydroxyimino) cyclopropa[b]chromen-1a-carboxylateethyl ester (CPCCOEt), (RS)-a-methyl-4-carboxyphenylglycine (MCPG), and (RS)-3,5-dihydroxyphenylglycine (DHPG) were purchased from Tocris (Ellisville, MO).

\section{Results}

ON stimulation produces a long-lasting EPSP in mitral cells

We used single stimuli (one pulse, $100 \mu \mathrm{s}$, $1-100 \mathrm{~V}$ ) to the ON layer to evoke responses in mitral cells. The duration and the amplitude of the evoked EPSP increased with the stimulus intensity (Fig. 1a). However, consistent with previous reports (Chen and Shepherd, 1997; Carlson et al., 2000; Schoppa and Westbrook, 2001), this stimulation produced longlasting synaptic depolarizations in mitral cells (duration $>1$ s) regardless of the strength of the stimulus. At threshold stimulus intensity that produced a response $\sim 50 \%$ of trials, EPSPs occurred in an "all-or-none" manner with an amplitude of $9.1 \pm 1.9 \mathrm{mV}$ and an integral of $4 \pm 1.1 \mathrm{mV} \cdot \mathrm{s}(n=6$; stimulation, $2-15 \mathrm{~V}$ ) (Fig. 1b). With maximal stimulation, responses (amplitude, $22.4 \pm 1.6 \mathrm{mV}$; integral, $32.9 \pm 3.6 \mathrm{mV} \cdot \mathrm{s}$ ) had a characteristic two-component shape with a slow phase that lasted $>10 \mathrm{~s}$ $(n=5)$ (Fig. $1 a$, top trace). ON stimulation also produced longlasting EPSCs in voltage-clamp recordings at -70 or $+50 \mathrm{mV}$ (Fig. 1c), indicating that voltage-gated channels in mitral cells were not primarily responsible for the long duration of the EPSC. The long-lasting component of the EPSC first emerged at postnatal day 10 (Fig. $1 d$ ), a period during which the complex anatomical compartmentalization of a glomerulus develops (Kim and Greer, 2000).

At resting potential, mitral cells respond to $\mathrm{ON}$ stimulation with prolonged spiking activity (Ennis et al., 1996; AroniadouAnderjaska et al., 1997). To evaluate dendritic release of glutamate during this response, we examined the subset of periglomerular (PG) neurons that primarily receive input from mitral cells rather than $\mathrm{ON}$ afferents, as determined by their relatively 
a

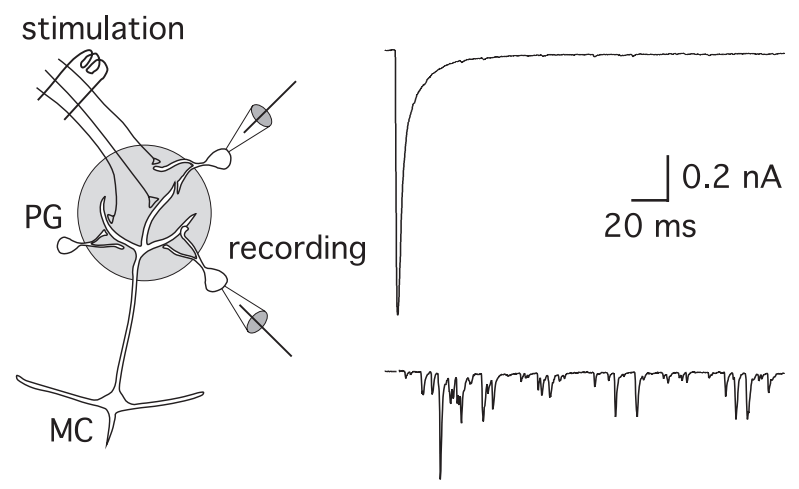

b
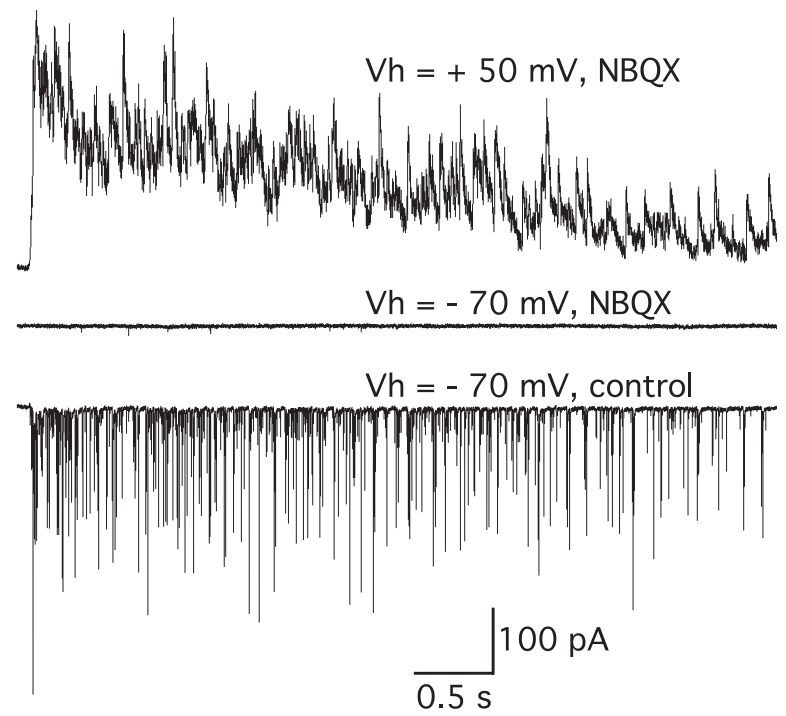

Figure 2. ON stimulation evokes ongoing release of glutamate from mitral cell dendrites. $\boldsymbol{a}$, Subsets of PG interneurons receive different inputs in the glomerulus (scheme) (see also Hayar et al., 2004). Some PG cells are directly contacted by $0 \mathrm{~N}$ terminals and respond to $0 \mathrm{~N}$ stimulation with a short-latency monosynaptic EPSC (right, top trace). Others are connected to mitral cells (MC) and respond with a long-latency burst of EPSCs (bottom trace). $\boldsymbol{b}$, At a longer time scale, the latter responded to a stimulation of the $0 \mathrm{~N}(8 \mathrm{~V})$ with a prolonged barrage of NBQX-sensitive EPSCs at $V_{\mathrm{h}}=-70 \mathrm{mV}$ (bottom trace) and a barrage of NMDA receptor-mediated EPSCs at $V_{\mathrm{h}}$ $=+50 \mathrm{mV}$ (top trace).

long, asynchronous, variable latency $(3.2 \pm 0.6 \mathrm{~ms} ; n=6)$ responses (Fig. 2a) (Hayar et al., 2004). In these cells, single stimuli evoked a prolonged barrage of EPSCs that included an AMPA component at $-70 \mathrm{mV}$ and an NMDA component that was apparent at $+50 \mathrm{mV}$ (Fig. $2 b$ ), consistent with ongoing secondary release of glutamate from mitral cells. In contrast, short-latency $(1.1 \pm 0.08 \mathrm{~ms} ; n=11)$ monosynaptic EPSCs recorded in PG cells that are directly contacted by olfactory afferents (Fig. 2a, top trace) suggested that $\mathrm{ON}$ stimulation triggers synchronous release of glutamate from $\mathrm{ON}$ nerve terminals.

mGluR1 and NMDA receptors mediate the slow component Although ON-evoked EPSCs in mitral cells have both a fast AMPA and a slow NMDA receptor component (Ennis et al., 1996; Aroniadou-Anderjaska et al., 1997; Chen and Shepherd, 1997), the duration of the EPSPs/EPSCs we observed was much longer than expected even with the slow kinetics of the NMDA receptor. Thus, we looked for other explanations for the duration of the mitral cell EPSP/EPSC. We first evaluated the contribution of metabotropic glutamate receptors. CPCCOEt, a selective
mGluR1 antagonist $(100 \mu \mathrm{M})$, reduced the integral of the evoked EPSP by $61 \pm 3 \%(n=22)$ (Fig. $3 a, b)$, principally affecting the slow component. The nonspecific mGluR antagonist MCPG (1-2 $\mathrm{mm})$ produced a similar inhibition $(52.4 \pm 6.7 \%$ reduction; $n=6)$. The inhibition did not correlate with stimulus strength or EPSP amplitude (Fig. 3b), suggesting that metabotropic glutamate receptors contribute to the EPSP regardless of the number of afferents stimulated. Accordingly, EPSPs evoked in mitral cells from mGluR1 knock-out mice (Conquet et al., 1994) had smaller slow components and decayed faster than in wild-type mice (Fig. $3 c, d)$.

However, mGluR1 was not exclusively responsible for the slow component, because EPSPs in mGluR1 knock-out mice (Fig. 3c) as well as the residual EPSPs recorded in the presence of an mGluR1 antagonist in wild-type mice (Fig. $3 a$ ) still lasted for several seconds. This residual slow component was entirely blocked by AP-5 (Fig. 3a,c). When both mGluR1 and NMDA receptors were inhibited, the mitral cell response consisted of a fast NBQX-sensitive AMPA receptor-mediated EPSP (Fig. 3c). These data thus indicate that mGluR1s, along with NMDA receptors, mediate the slow component of the mitral cell response.

\section{Activation of mGluR1s is not monosynaptic}

Our results were somewhat puzzling because synaptic activation of mGluR1 in other pathways typically requires trains of stimuli (Batchelor and Garthwaite, 1997; Brasnjo and Otis, 2001; Dzubay and Otis, 2002; Huang et al., 2004). Furthermore, as discussed above, the mitral cell response evoked by $\mathrm{ON}$ stimulation is usually completely blocked by NMDA and AMPA receptor antagonists (Chen and Shepherd, 1997; Carlson et al., 2000; Schoppa and Westbrook, 2001; De Saint Jan and Westbrook, 2005). However, a small mGluR1-mediated EPSP was occasionally observed in previous experiments in the presence of NBQX $(20 \mu \mathrm{M})$ and AP-5 $(150 \mu \mathrm{M})$, conditions that prevent release of glutamate from postsynaptic mitral/tufted cell dendrites (De Saint Jan and Westbrook, 2005). In our experiments, the size of this small mGluR1 response, evoked in the presence of NBQX and AP-5, increased in response to short $100 \mathrm{~Hz}$ stimulus trains (3-10 stimuli) (Fig. 4a) or when glutamate transporters were blocked with $\mathrm{D}, \mathrm{L}-\mathrm{threo}-\beta$ benzyloxyaspartate (TBOA) (Fig. 4b) (De Saint Jan and Westbrook, 2005). The mGluR1-mediated EPSP isolated in the presence of AP-5 and NBQX saturated after only three to five ON stimuli (Fig. 4a), but this response was still smaller than the response blocked by CPCCOEt in the control EPSP $(5 \pm 0.5 \mathrm{mV} \cdot \mathrm{s}$, $n=11$ vs $8.9 \pm 1 \mathrm{mV} \cdot \mathrm{s}, n=22$, respectively; $p=0.002)$. The duration of the train-evoked mGluR1-mediated EPSP was further prolonged by TBOA $(100 \mu \mathrm{M})$ reaching amplitudes $(9.1 \pm$ $1.9 \mathrm{mV} \cdot \mathrm{s} ; n=4)$ comparable to the mGluR1 component of the control response (Fig. $4 b$ ). Thus, in the absence of glutamate release from dendrites, ON-stimulated mGluR1 responses appear similar to other pathways where mGluR1s are located at the periphery of the postsynaptic density (Baude et al., 1993; Batchelor and Garthwaite, 1997; Brasnjo and Otis, 2001; Dzubay and Otis, 2002; Huang et al., 2004). Our data are also consistent with ultrastructural data (van den Pol, 1995) suggesting that mitral cell mGluR1s are located on postsynaptic membranes facing ON terminals. However, this does not resolve why mGluRs make such a prominent contribution to mitral cell EPSPs evoked by a single stimulus.

The olfactory circuitry is unusual in that ON stimulation triggers release of glutamate from two sources, the ON nerve terminal itself and the dendrites of activated mitral cells. Glutamate release sites on mitral cell dendrites can occur near axodendritic 

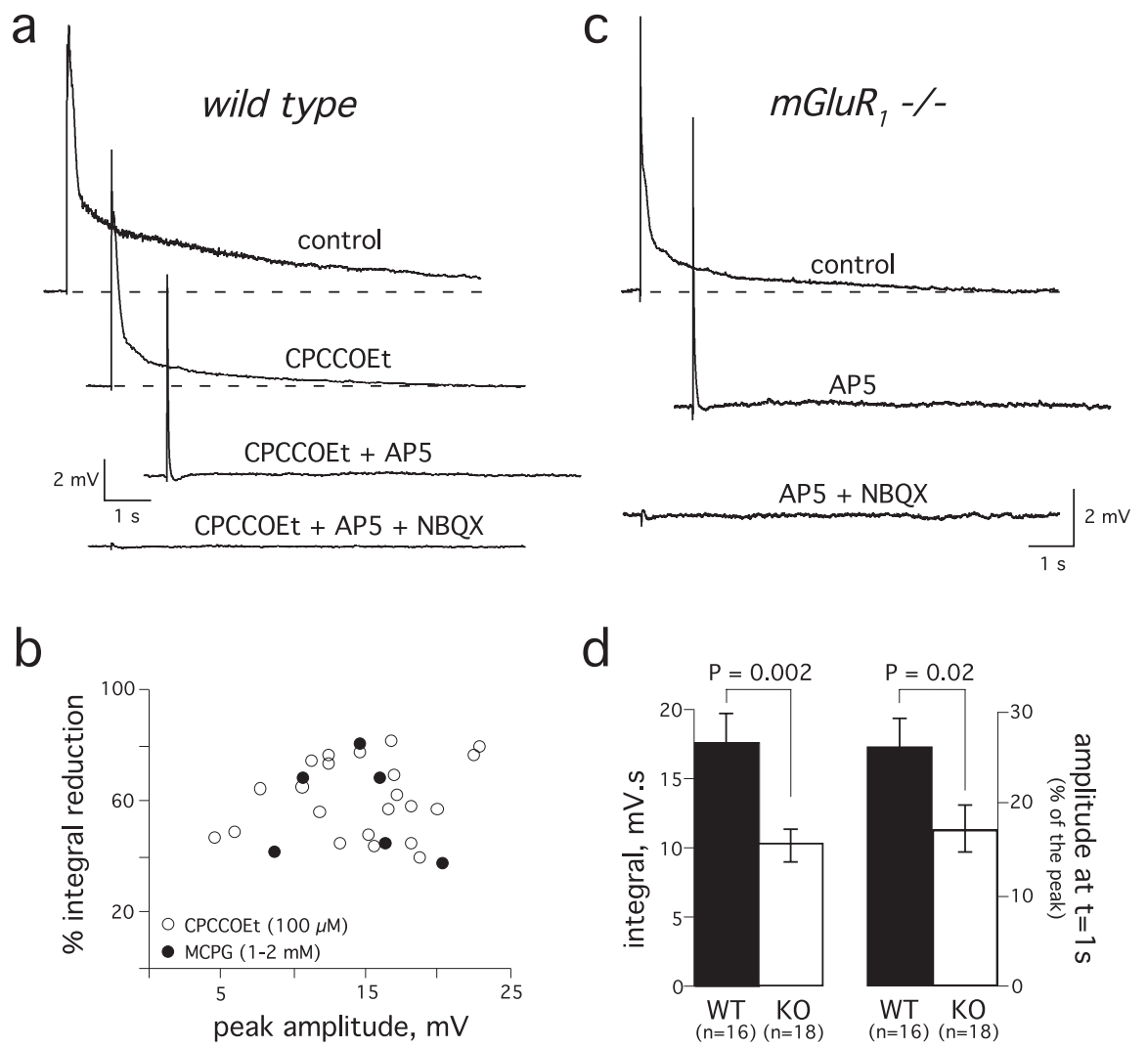

Figure 3. mGluR1 activation contributes to the synaptic depolarization of mitral cells. $\boldsymbol{a}$, Top trace, The mGluR1-specific antagonist CPCCOEt $(100 \mu \mathrm{M})$ reduced the mitral cell EPSP (second trace). The remaining slow component was blocked by the NMDA receptor antagonist AP-5 (150 $\mu \mathrm{m}$, third trace). The fast EPSP that persisted in the presence of CPCCOEt and AP-5 was blocked by the AMPA receptor antagonist NBQX ( $20 \mu \mathrm{m}$, bottom trace). $\boldsymbol{b}$, Inhibition by CPCCOEt or MCPG did not correlate with the amplitude of the mitral cell EPSP. c, In mGluR ${ }^{-1-}$ mice, the prolonged component of the ON-evoked mitral cell EPSP was entirely blocked by AP-5 $(150 \mu \mathrm{M})$. NBQX $(20 \mu \mathrm{m})$ inhibited the fast EPSP. $\boldsymbol{d}$, Left, The integral of the EPSP was larger in wild type (WT) than in mGluR1 ${ }^{-1-}$ mice (KO). Right, The amplitude at $t=1$ s normalized to the peak amplitude was smaller in knock-out mice (KO) than in wild type (WT). Responses with similar peak amplitudes (WT: $15.5 \pm 0.5 \mathrm{mV}, n=16 ; \mathrm{KO}: 14.4 \pm 0.5 \mathrm{mV}, n=18 ; p>0.05$ ) were selected for these comparisons.


Figure 4. Synaptic activation of mGluR1 in the presence of ionotropic GluR blockers. $\boldsymbol{a}$, Left, The mitral cell EPSP (inset) was nearly abolished by NBQX (20 $\mu \mathrm{M})$ and AP-5 $(150 \mu \mathrm{M})$. Trains of stimuli (stim.; 3,5 , or 10 stimuli at $100 \mathrm{~Hz}$ ) increased the small residual EPSP, which was attributable to activation of mGluR1 (bottom traces). Right, Integral of the mGluR1-mediated EPSP evoked by single or multiple stimulations reached a maximum size after three stimuli (number of cells in parentheses). $\boldsymbol{b}$, Inhibition of glutamate transporters with TBOA $(100 \mu \mathrm{m})$ prolonged the duration of the mGluR1-mediated EPSP evoked by a train of stimuli (integral, $235 \pm 35 \%$ of control; $n=4$ ) without affecting its amplitude ( $109 \pm 5.1 \%$ of control; $n=4)$.

synapses between ON axons and mitral cells [Montague and Greer, (1999), their Fig. 2]. We therefore tested whether dendritic release of glutamate from a mitral cell could activate mGluR1s. Consistent with a previous report (Salin et al., 2001), direct depolarization of a mitral cell soma $(10-500 \mathrm{~ms})$ produced a fast autoexcitatory potential that was fully blocked by AP-5 and NBQX but not by CPCCOEt or MCPG. Thus, glutamate release from dendrites of a single mitral cell was not sufficient to activate mGluR1s $(n=6$; data not shown). Likewise, a depolarizing step delivered before stimulation of the ON did not potentiate mGluR1-mediated EPSPs isolated in the presence of AP-5 and NBQX ( $n=4$; data not shown), suggesting that the glutamate released from one mitral cell did not significantly facilitate the activation of mGluR1s. These data are also consistent with a recent study (Yuan and Knopfel, 2006) indicating that elevation of intracellular calcium does not potentiate the metabotropic EPSP as in other pathways (Batchelor and Garthwaite, 1997; Huang et al., 2004).

If mitral cell mGluR1s are expressed on postsynaptic membranes facing sensory nerve terminals, our results suggest that mGluR1s would have to be activated for a prolonged period of time to account for their major contribution after ON stimulation. Because this cannot be achieved by glutamate released from only the olfactory axon terminals after a single stimulation, another source of glutamate must participate in mGluR1 activation. Direct support for this hypothesis is illustrated in Figure 5. The NMDA receptor antagonist AP-5 $(150 \mu \mathrm{M})$ reduced the ON-evoked response by $86 \pm 2 \%(n=7)$ (Fig. $5 a)$. In the presence of $\mathrm{AP}-5$, the response in wild-type mice consisted of a fast EPSP, followed by a slow depolarization. The latter (integral, $4.2 \pm 0.9 \mathrm{mV} \cdot \mathrm{s} ; n=8$ ) was absent in mGluR1 knock-out mice $(n=$ 9) and blocked by the mGluR1 blockers LY367385 (25-50 $\mu \mathrm{M} ; n=4)$ or CPCCOEt (100 $\mu \mathrm{M} ; n=4)$ in wild-type mice. NBQX inhibited the fast component, as expected, but it also reduced the mGluR1mediated component (Fig. 5b). Thus, a disynaptic pathway initiated by ON input, is required for the full expression of the mGluR1-mediated EPSP in mitral cells.

\section{Intraglomerular spillover of glutamate prolongs the ON-evoked EPSP}

Within a glomerulus, mitral cells receive excitatory synaptic inputs from olfactory sensory afferents. However, concerted mitral cell excitation can cause spillover of dendritically released glutamate, resulting in a slow depolarization (Christie and Westbrook, 2006). We therefore hypothesized that glutamate released from the intraglomerular network of mitral/tufted cells might diffuse and prolong the activation of mGluR1s and NMDA receptors at axodendritic synapses. Indeed, we observed spontaneous longlasting depolarizations that were similar in size and shape to the ON-evoked EPSPs (Fig. 6a). As first reported by Carlson et al. (2000), the frequency of these spontaneous events dramatically 
a

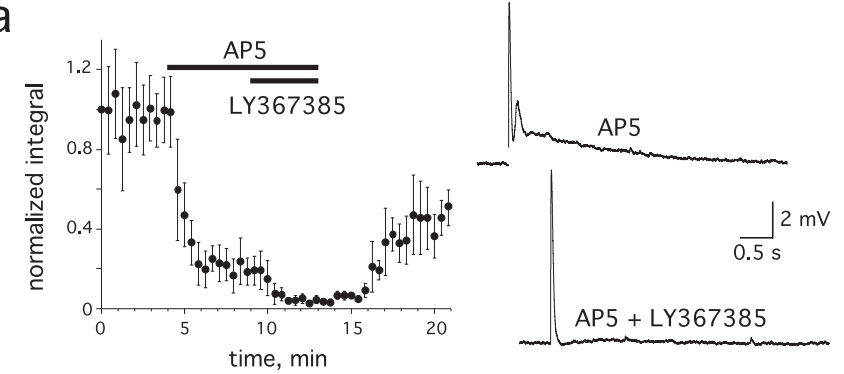

b



Figure 5. mGluR1 activation in the presence of the NMDA receptor antagonist AP-5. $\boldsymbol{a}$, Left, AP-5 $(150 \mu \mathrm{M})$ inhibited $>80 \%$ of the mitral cell EPSP evoked by ON stimulation. Right, The remaining slow component (top trace) was selectively blocked by the mGluR1-specific antagonist LY367385 (25-50 $\mu \mathrm{m}$; bottom trace). $\boldsymbol{b}$, Left, NBQX (20 $\mu \mathrm{m}$ ) blocked not only the fast component but also the mGluR1 component as recorded in the presence of AP-5. Right, NBQX inhibition of the slow EPSP for six cells in the presence of AP-5.

increased when $\mathrm{GABA}_{\mathrm{A}}$ receptors were blocked ( $2 \mu \mathrm{M}$ gabazine; data not shown). The currents underlying the spontaneous events reversed at positive holding potential (Fig. 6b), indicating that they were driven by glutamate-mediated currents, rather than by voltage-gated channels or electrical coupling. Spontaneous depolarizations occurred synchronously in pairs of cells projecting to the same glomerulus ( $n=8$ pairs) (Fig. $6 a)$, consistent with intraglomerular glutamate release. Finally, spontaneous depolarizations had slower rise times $(20-80 \%$ rise time, $21.6 \pm 3.9$ $\mathrm{ms} ; n=8)$ than evoked EPSPs $(20-80 \%$ rise time, $2.6 \pm 0.7 \mathrm{~ms}$; $n=30$ ) (Fig. 6a).

If spillover of dendritically released glutamate mediates the slow component of the mitral cell response, then the mitral cell EPSP should be shorter in conditions of reduced spillover. Mitral cell apical dendrites are electrically coupled by gap junctions formed by connexin36 (Christie et al., 2005). In the absence of connexin36, glutamate spillover between mitral cell dendrites is strongly reduced (Christie and Westbrook, 2006). When matched to the amplitude of the fast AMPA-receptor mediated EPSP, the slow components of ON-evoked EPSPs in Cx36 ${ }^{-1-}$ mice were markedly reduced in amplitude and duration (Fig. $6 c, d)$. These results suggest that mGluR1s and NMDA receptors are not as robustly activated in the absence of the electrically coupled mitral cell network. The contribution of mGluR1 to submaximal responses could not be accurately measured using mGluR1 antagonists because of the small size of the slow component. However, a 10-stimuli train did evoke mGluR1-mediated EPSPs (data not shown). Moreover, exogenous application of DHPG $(200 \mu \mathrm{M})$ within a glomerulus generated an inward CPCCOEt-sensitive current ( $n=3$; data not shown), indicating that mGluR1s were present on mitral cell dendrites in $\mathrm{Cx} 36^{-1-}$ animals.

The ON-evoked EPSC recorded at a positive holding potential in wild-type mice also exhibited two distinct components, a first component consistent with a monosynaptic NMDA receptormediated EPSC and a slower and longer component $(n=7)$ (Fig. $6 e)$. In contrast, the response in connexin $36^{-1-}$ mice lacked the slow component, suggesting it was caused by glutamate released from the glomerular network $(n=5)$ (Fig. 6f). To demonstrate this interpretation, we used magnesium as a voltage-dependent channel blocker of NMDA receptors (Mayer and Westbrook, 1985). This divalent cation should not block NMDA receptors in the cell recorded at a positive potential but reduce the excitability of the network and, indirectly, dendritic release. The slow component of the wild-type response was selectively blocked by increasing external magnesium from 1 to $3 \mathrm{~mm}$ (half-width, $30 \pm$ $14 \%$ of control; $n=3$ ) (Fig. $6 e$ ). In contrast, magnesium did not affect the early phase of the response, suggesting that glutamate release from olfactory neurons was not reduced (Fig. 6e).

Nickel $(300 \mu \mathrm{M})$ also blocked the slow component of the mitral cell EPSC recorded at a positive potential (half-width, $24 \pm$ $7 \%$ of control; $n=4$ ) (Fig. $7 d$ ) as well as the slow phase of the EPSP recorded in current clamp (Fig. 7c). In both conditions, the early phase of the response was unaffected. Nickel is a potent NMDA receptor channel blocker (Mayer and Westbrook, 1985), but it also inhibits some voltage-activated calcium channels. Its effect on the mitral cell response could thus be explained by an inhibition of glutamate release at ON terminals or at mitral cell dendrites. To test these possibilities, we first analyzed the action of nickel ( $300 \mu \mathrm{M})$ on ON-evoked monosynaptic EPSCs recorded from PG neurons directly contacted by ON terminals. Similar to magnesium, nickel had no significant effect on monosynaptic EPSCs evoked in these PG cells $(n=5)$ (Fig. 7a). We then used PG neurons that receive input from mitral cells to examine the action of nickel on dendritic release. EPSCs evoked in this subset of PG cells by extracellular stimulation of the mitral cells were blocked by nickel (Fig. $7 c)(n=4)$. Therefore, the effect of nickel on the mitral cell response could be explained by its action on NMDA receptors as well as its inhibition of dendritic release of glutamate.

Altogether, these data support the hypothesis that ON-evoked mitral cell responses are initiated by release of glutamate from the olfactory axon terminals and prolonged by glutamate released by the intraglomerular network of mitral and tufted cells. This recurrent excitation, likely mediated by spillover of glutamate onto mitral cells, is necessary for the expression of the mGluR1mediated EPSP and also prolongs the activation of the NMDA receptor.

\section{Discussion}

The topographic organization of the olfactory system is well conserved along species (Ache and Young, 2005). In particular, the map of sensory neurons onto specific glomeruli suggests that these anatomical specializations play fundamental roles in odor processing. Cellular studies clearly indicate that glomeruli can synchronize the output of mitral cells over wide time scales from seconds (Schoppa and Westbrook, 2001) to milliseconds (Schoppa and Westbrook, 2002; Christie et al., 2005). Our experiments demonstrate a previously unappreciated role for mGluRs in generating long-lasting synaptic excitation in mitral cells. The mGluR1-mediated disynaptic responses in mitral cells are likely contributors to amplify incoming sensory information and to impose temporal pattern of activity in the olfactory bulb.

\section{Long-lasting synaptic responses}

At most excitatory synapses, a single stimulus evokes a brief transient of glutamate (Clements et al., 1992) that activates postsyn- 
a

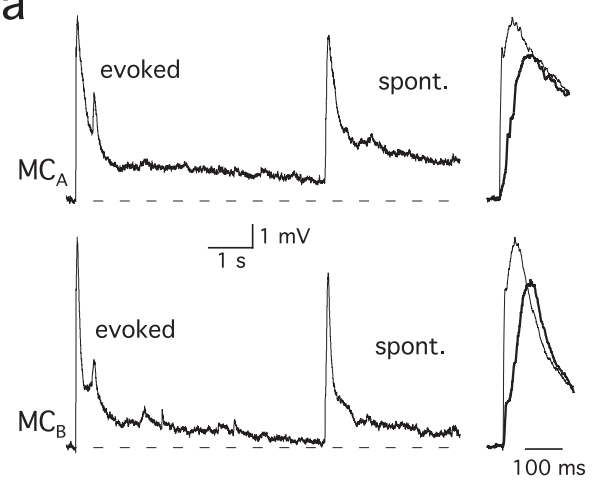

b

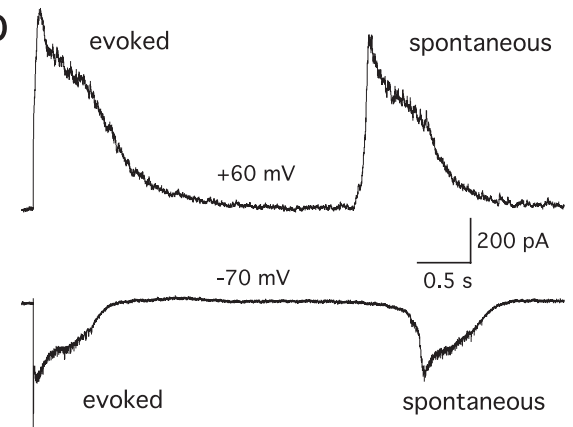

C

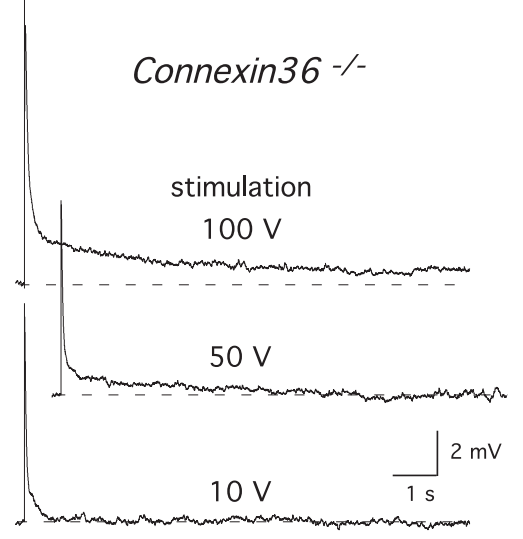

d
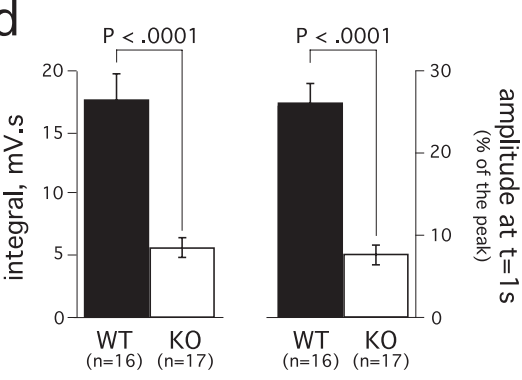

e

wild type

$\mathrm{Vh}=+50 \mathrm{mV}$, control

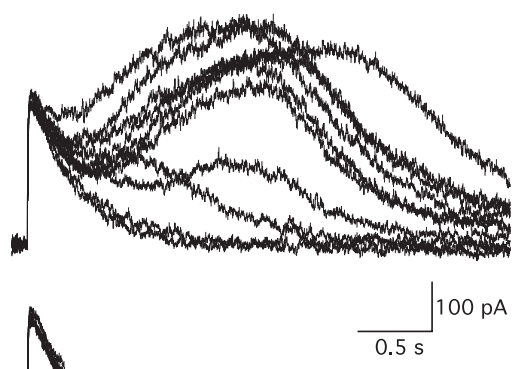

$\mathrm{Vh}=+50 \mathrm{mV}, \mathrm{Mg}^{2+}$
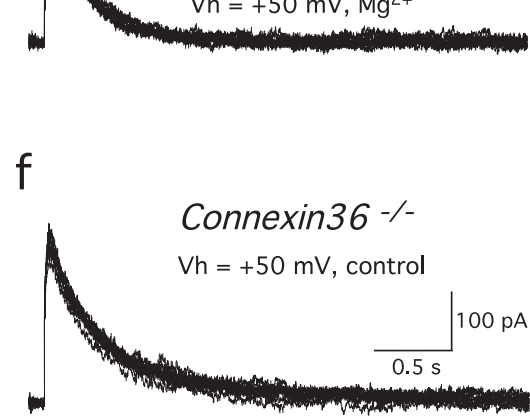

Figure 6. The intraglomerular network generates glutamatergic inputs onto mitral cell dendrites. $\boldsymbol{a}$, Left, Spontaneous (spont.) depolarizations in a pair of mitral cells projecting to the same glomerulus had a similar time course to the evoked EPSPs. Note also that the depolarization were synchronous in the two cells. Right, Evoked events (thin traces) had faster rise times than spontaneous events (thick traces). $\boldsymbol{b}$, In voltage clamp, spontaneous and ON-evoked currents also had similar shapes and reversed polarity at positive holding potentials (top trace). $\boldsymbol{c}$, EPSPs were evoked by a single stimulation of the $0 \mathrm{~N}$ at different intensities in a mitral cell from a connexin 36 knock-out mouse. $\boldsymbol{d}$, Comparison of the integral (left) and decay (right) of EPSPs evoked in wild-type (WT) or $\mathrm{Cx} 36^{-1-}$ (KO) mice. As in Figure 3, the ratio of the EPSP amplitude at $t=1 \mathrm{~s}$ and peak amplitude were used as a measure of the response duration. Responses with similar amplitude (WT: same as in Fig. 3; K0: $14.7 \pm 0.5 \mathrm{mV}, n=17, p>0.1$ ) were selected for comparison. $e, 0 \mathrm{~N}$-evoked EPSCs in a wild-type mitral cell recorded at $V_{\mathrm{h}}=+50 \mathrm{mV}$ in control solution (i.e., $1 \mathrm{~mm}$ external $\mathrm{Mg}^{2+}$; top traces). Most, but not all, responses exhibited a slow component that prolongs the NMDA receptor-mediated-EPSC. Increasing extracellular Mg ${ }^{2+}$ from $1 \mathrm{~mm}$ to 3 mm (bottom traces) selectively blocked the slow current responsible for the prolonged decay of the EPSC. Ten consecutive responses are shown in each condition. $f$, A series of 15 EPSCs recorded at $+50 \mathrm{mV}$ in a connexin $36^{-1-}$ mouse lacked the slow components observed in wild-type animals. Solutions for recordings in $\boldsymbol{b}, \boldsymbol{e}$, and $\boldsymbol{f}$ included gabazine $(2 \mu \mathrm{m})$.

aptic AMPA receptors and a short depolarization and, in some cases, the higher-affinity NMDA receptors that mediate a slow voltage-dependent current. However, the latter response rarely exceeds a few hundred milliseconds (Cull-Candy and Leszkiewicz, 2004). G-protein-coupled metabotropic glutamate receptors can generate much slower postsynaptic currents lasting several seconds (Anwyl, 1999). However, their perisynaptic localization (Baude et al., 1993) appears to limit their activation, at least in acute slices, unless high-frequency stimulation is applied to presynaptic neurons or diffusion is enhanced by block of glutamate transporters. Synaptic activation of mGluRs appears easier to elicit in organotypic slice cultures (Charpak and Gahwiler, 1991; Miller et al., 1995), although sprouting and aberrant targeting might explain this difference.

Long-lasting excitatory synaptic responses have been observed at synapses with specialized ultrastructural features. For instance, at giant synapses between a cerebellar mossy fiber and unipolar brush cell, the unique synaptic architecture delays glutamate clearance and increases the duration of the EPSP. Accumulation of glutamate enables multiple binding onto NMDA and AMPA receptors that generate a response that lasts several seconds (Rossi et al., 1995). Olfactory bulb glomeruli contain a synaptic circuitry that also exhibits unique features that might promote glutamate pooling. The olfactory axon terminals with their high-release probability (Murphy et al., 2004) are often clustered along dendrites and can be located close to dendrodendritic synapses where glutamate is also released (Giustetto et al., 1997;
Kasowski et al., 1999; Montague and Greer, 1999). Glial processes are most often absent between adjacent ON boutons (Chao et al. 1997; Kasowski et al., 1999) but can be intermingled between axodendritic and dendrodendritic synapses (De Saint Jan and Westbrook, 2005). However, this apparent diffusional barrier between axodendritic and dendrodendritic synapses may be easily overwhelmed by sustained stimulation (De Saint Jan and Westbrook, 2005). Glial-free compartments within glomeruli might then constitute preferred pathways for glutamate diffusion (Chao et al. 1997; Kasowski et al., 1999).

\section{The contribution of mGluRs and NMDA receptors to long-} lasting synaptic depolarization in mitral cells

As demonstrated by astrocytic recording of transporter currents, stimulation of the ON produces two transients of glutamate at short intervals (1-2 ms) within a glomerulus (De Saint Jan and Westbrook, 2005). The first is caused by release of glutamate at olfactory axon terminals, whereas the second reflects concerted release by mitral and tufted cell dendrites. Electrical coupling among mitral and tufted cell dendrites ensures that principal neurons within a glomerulus can respond to sensory inputs as a single unit and release glutamate in a concerted manner (Christie and Westbrook, 2006). In addition, the response of this glomerular network might well be driven and synchronized by highly excitable external tufted cells (Hayar et al., 2004). These two initial transients might work together in saturating glutamate transporters that limit spillover (Christie and Westbrook, 2006) and 
limit activation of mGluR1 (De Saint Jan and Westbrook, 2005; Ennis et al., 2006; Yuan and Knopfel, 2006). Once transporters are overwhelmed, the two sources of glutamate could cooperate, leading to activation of mGluR1s. This scenario assumes that $\mathrm{mGluR} 1$ receptors are located at axodendritic synapses between olfactory axon terminals and mitral cell dendrites. Electron microscopy data support this assumption (van den Pol, 1995). This is also consistent with functional results indicating that dendritic release of glutamate from an ensemble of mitral cells activates NMDA and AMPA receptors but not mGluR1s (Christie and Westbrook, 2006; Ennis et al., 2006).

Our results suggest that NMDA receptors equally contribute to the slow component of the mitral cell response. This long-lasting NMDA-mediated component implies multiple binding of glutamate onto NMDA receptors. The presence of ambient glutamate within the axodendritic or dendrodendritic compartments where NMDA receptors are expressed (Giustetto et al., 1997) could drive such prolonged activation. Low-affinity antagonist experiments suggest that glutamate released at dendrodendritic synapses can diffuse into neighboring compartments (Schoppa and Westbrook, 2001). Because ongoing release of glutamate lasts for seconds at dendrodendritic synapses as shown in our experiments, sustained release of glutamate could provide a low concentration of transmitter within dendritic compartments. mGluR1 activation as well as dendritic autoexcitation (Isaacson, 1999; Schoppa and Westbrook, 2001; Salin et al., 2001) and electrical coupling (Schoppa and Westbrook, 2002; Christie et al., 2005) favor this regenerative release of glutamate.

\section{The importance of a \\ glomerular amplifier}

Sensory systems use a variety of mechanisms to amplify weak but specific external stimuli. For instance, in the auditory system, mechanical and molecular properties of the cochlea make it a powerful amplifier (LeMasurier and Gillespie, 2005). In the visual system, the phototransduction cascade insures that a single photon causes a substantial electric response in a photoreceptor, and synaptic circuits in the retina further amplify this signal (Sterling, 2004). The ability of the olfactory system to detect and discriminate low concentration of odorants suggests that olfaction can amplify incoming signals. However, olfactory neurons are a
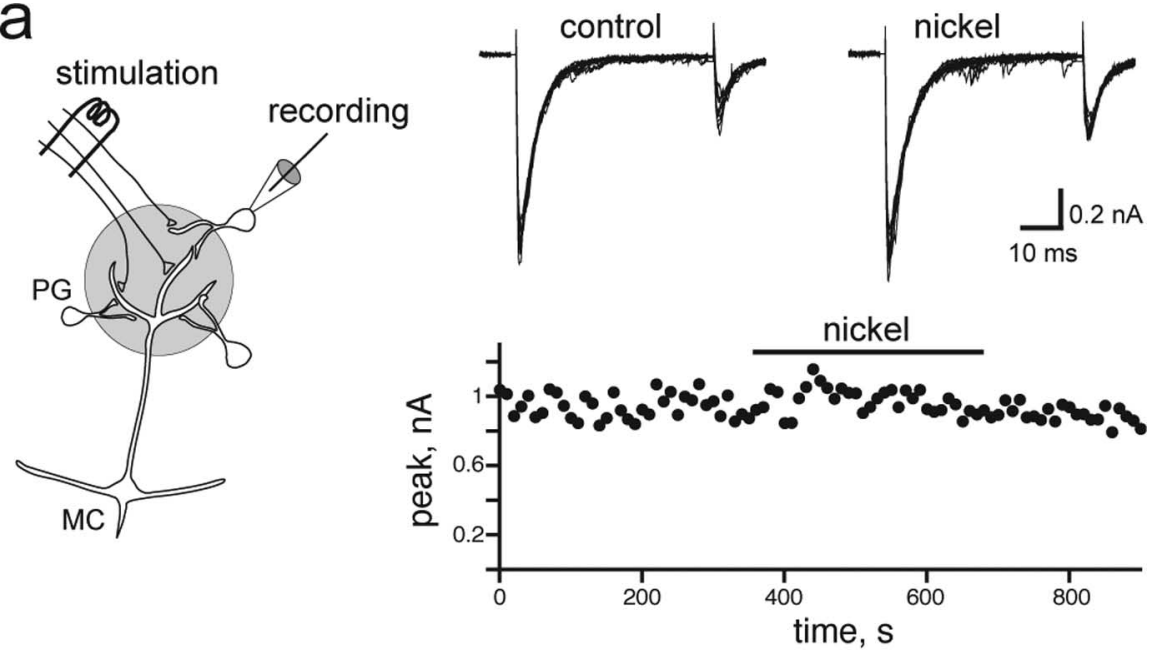

b

control nickel wash
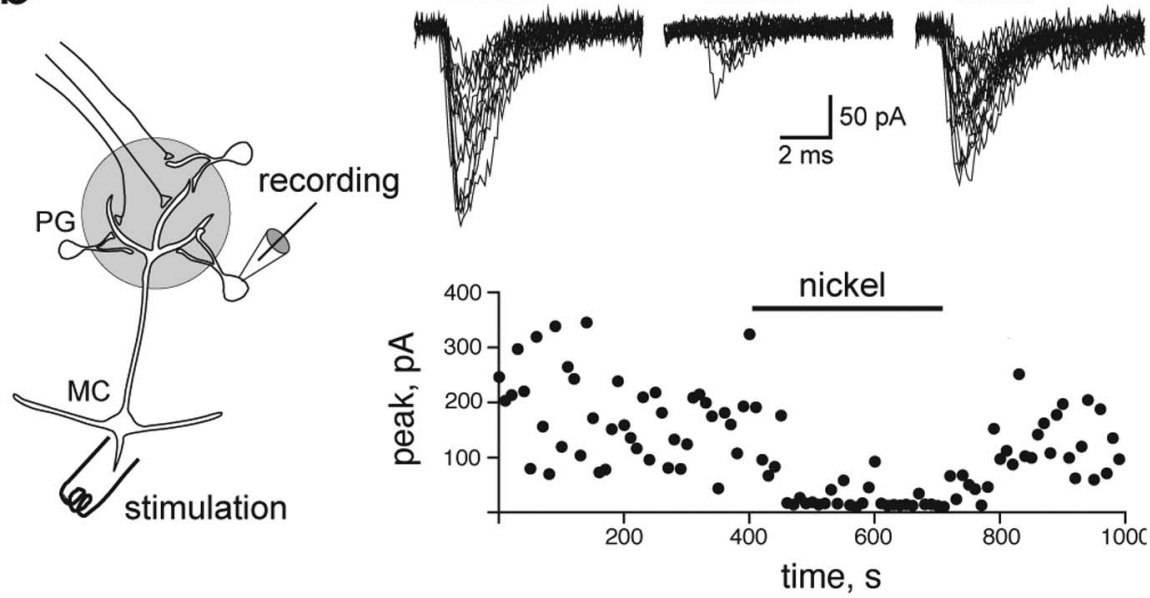

C
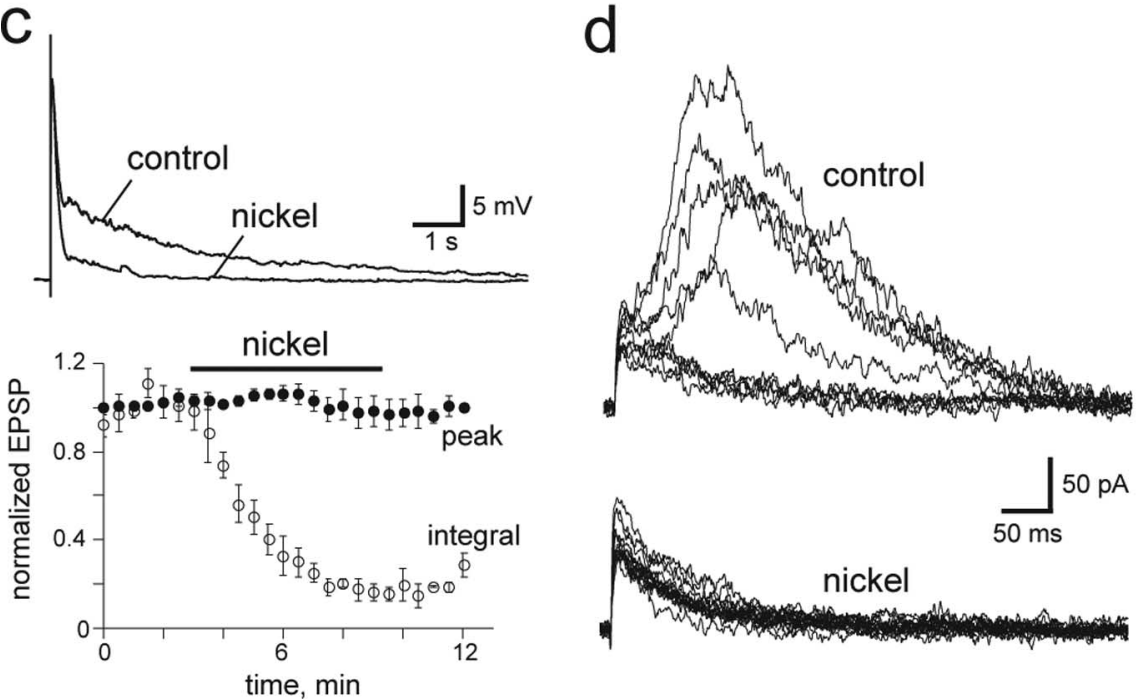

nickel

Figure 7. Selective inhibition of dendritic release reduced the slow component of the mitral cell response. $\boldsymbol{a}$, Nickel had no effect on the amplitude and paired-pulse ratio of EPSCs evoked by ON stimulation in a PG neuron that received monosynaptic input from ON terminals (scheme). Twelve consecutive traces are shown in control conditions and in the presence of nickel. $\boldsymbol{b}$, In a PG neuron synaptically connected to mitral cells (MC; scheme), nickel blocked the EPSC evoked by an extracellular stimulation (1 pulse, 100 $\mu s$ ) in the mitral cell layer. Ten consecutives traces are shown in each condition. c, Top, Inhibiton by nickel of the ON-evoked mitral cell EPSP. Nickel reduced the integral of the response (bottom, opened circles) but not the peak of the response $(\boldsymbol{O} ; n=6)$. $\boldsymbol{d}$, Series of consecutive $0 \mathrm{~N}$-evoked EPSCs in a mitral cell recorded in voltage clamp at $V_{\mathrm{h}}=+50 \mathrm{mV}$ in control condition (top traces) or in the presence of nickel (bottom traces). The nickel concentration was $300 \mu \mathrm{m}$ in all experiments. 
intermittently exposed to variable concentrations of an odorant as the animal moves through the medium and turbulent air-flows carry odorant molecules. Furthermore, signal amplification does not seem to take place at the level of olfactory neurons because of the low efficacy with which olfactory receptors translate odorant binding into biochemical (Takeuchi and Kurahashi, 2005) and electrical (Bhandawat et al., 2005) signals. The high number of olfactory neurons expressing a given olfactory receptor may compensate for this low efficacy. However, a short dwell time of odorants on their receptors implies that only a fraction will be activated and for short periods of time (Bhandawat et al., 2005). Nonetheless, odorants can elicit mitral cell activity that greatly exceed the duration of the odor presentation (Luo and Katz, 2001; Charpak et al., 2001). Similar patterns occur in projection neurons in invertebrates (Laurent et al., 1996; Wilson et al., 2004). The long-lasting excitation of mitral cells might thus be critical for amplification of a weak sensory stimulus.

It remains to be determined whether the temporal asynchrony that likely characterizes an olfactory input in vivo triggers the same mechanism as a single electrical stimulus in slices that generate synchronous spikes in a fraction of ONs. Several pieces of evidence argue it might be the case. First, long-lasting depolarizations are evoked by low-intensity stimulation in slices, suggesting their occurrence does not depend on the incoming input. Second, odors evoke low field potential oscillations in rodent olfactory bulb or in insect antennal lobe (Laurent et al., 2001). These oscillations reflect synchronize firing across a population of cells driven by ON-evoked excitation. Similar patterns of oscillatory activity are observed in slices stimulated electrically (Lagier et al., 2004), suggesting similar circuits are recruited in vivo and in vitro. Moreover, they are absent in young animals in vivo (Fletcher et al. 2005), similar to long-lasting depolarization in vitro (Fig. $1 d$ ), suggesting they might be driven in older animals by slow EPSPs in mitral cells.

\section{Physiological significance of persistent activity in mitral cells} Physiological studies suggest that the slow temporal pattern of activity encode several features of an odorant (Laurent et al., 2001) and imply that time is required for odor discrimination (Friedrich and Laurent, 2001; Friedrich, 2006). In contrast behavioral studies indicate that olfactory discrimination is fast ( $200 \mathrm{~ms}$ ) (Uchida and Mainen, 2003; Abraham et al., 2004), although seemingly at the expense of accuracy for closely similar odors (Uchida and Mainen, 2003; Abraham et al., 2004; Khan and Sobel, 2004). Accordingly, odor identification seems intact in young rats in which odors do not evoke slow patterns of activity (Fletcher et al., 2005). These studies raise the question of the benefit of slow neural processes. However, the slow temporal pattern of activity might be important for the discrimination of a novel stimulus or to identify an odor in a rich olfactory background (Khan and Sobel, 2004) (i.e., in conditions that were not studied in the behavioral studies mentioned above). Moreover, persistent activity in mitral cells may favor synaptic plasticity in the olfactory cortex and therefore be crucial for olfactory memory (Dubnau et al., 2003). Connexin36-deficient mice might serve as good model to test these hypotheses because the temporal aspect of their mitral cell responses is likely to be altered.

\section{References}

Abraham NM, Spors H, Carleton A, Margrie TW, Kuner T, Schaefer AT (2004) Maintaining accuracy at the expense of speed: stimulus similarity defines odor discrimination time in mice. Neuron 44:865-876.

Ache BW, Young JM (2005) Olfaction: diverse species, conserved principles. Neuron 48:417-430.
Anwyl R (1999) Metabotropic glutamate receptors: electrophysiological properties and role in plasticity. Brain Res Brain Res Rev 29:83-120.

Aroniadou-Anderjaska V, Ennis M, Shipley MT (1997) Glomerular synaptic responses to olfactory nerve input in rat olfactory bulb slices. Neuroscience 79:425-434.

Axel R (2005) Scents and sensibility: a molecular logic of olfactory perception (Nobel lecture). Angew Chem Int Ed Engl 44:6110-6127.

Batchelor AM, Garthwaite J (1997) Frequency detection and temporally dispersed synaptic signal association through a metabotropic glutamate receptor pathway. Nature 385:74-77.

Baude A, Nusser Z, Roberts JD, Mulvihill E, McIlhinney RA, Somogyi P (1993) The metabotropic glutamate receptor (mGluRl alpha) is concentrated at perisynaptic membrane of neuronal subpopulations as detected by immunogold reaction. Neuron 11:771-787.

Bhandawat V, Reisert J, Yau KW (2005) Elementary response of olfactory receptor neurons to odorants. Science 308:1931-1934.

Brasnjo G, Otis TS (2001) Neuronal glutamate transporters control activation of postsynaptic metabotropic glutamate receptors and influence cerebellar long-term depression. Neuron 31:607-616.

Buck LB (2005) Unraveling the sense of smell (Nobel lecture). Angew Chem Int Ed Engl 44:6128-6140.

Carlson GC, Shipley MT, Keller A (2000) Long-lasting depolarizations in mitral cells of the rat olfactory bulb. J Neurosci 20:2011-2021.

Chao TI, Kasa P, Wolff JR (1997) Distribution of astroglia in glomeruli of the rat main olfactory bulb: exclusion from the sensory subcompartment of neuropil. J Comp Neurol 388:191-210.

Charpak S, Gahwiler BH (1991) Glutamate mediates a slow synaptic response in hippocampal slice cultures. Proc Biol Sci 243:221-226.

Charpak S, Mertz J, Beaurepaire E, Moreaux L, Delaney K (2001) Odorevoked calcium signals in dendrites of rat mitral cells. Proc Natl Acad Sci USA 98:1230-1234.

Chen WR, Shepherd GM (1997) Membrane and synaptic properties of mitral cells in slices of rat olfactory bulb. Brain Res 745:189-196.

Christie JM, Westbrook GL (2006) Lateral excitation within the olfactory bulb. J Neurosci 26:2269-2277.

Christie JM, Bark C, Hormuzdi SG, Helbig I, Monyer H, Westbrook GL (2005) Connexin 36 mediates spike synchrony in olfactory bulb glomeruli. Neuron 46:761-772.

Clements JD, Lester RA, Tong G, Jahr CE, Westbrook GL (1992) The time course of glutamate in the synaptic cleft. Science 258:1498-1501.

Conquet F, Bashir ZI, Davies CH, Daniel H, Ferraguti F, Bordi F, Franz-Bacon K, Reggiani A, Matarese V, Conde F, Collingridge GL, Crépel F (1994) Motor deficit and impairment of synaptic plasticity in mice lacking mGluR1. Nature 372:237-243.

Cull-Candy SG, Leszkiewicz DN (2004) Role of distinct NMDA receptor subtypes at central synapses. Sci STKE 255:re16.

De Saint Jan D, Westbrook GL (2005) Detecting activity in olfactory bulb glomeruli with astrocyte recording. J Neurosci 25:2917-2924.

Dubnau J, Chiang AS, Tully T (2003) Neural substrates of memory: from synapse to system. J Neurobiol 54:238-253.

Dzubay JA, Otis TS (2002) Climbing fiber activation of metabotropic glutamate receptors on cerebellar Purkinje neurons. Neuron 36:1159-1167.

Ennis M, Zimmer LA, Shipley MT (1996) Olfactory nerve stimulation activates rat mitral cells via NMDA and non-NMDA receptors in vitro. NeuroReport 7:989-992.

Ennis M, Zhu M, Heinbockel T, Hayar A (2006) Olfactory nerve-evoked metabotropic glutamate receptor-mediated synaptic responses in rat olfactory bulb mitral cells. J Neurophysiol 95:2233-2241.

Fletcher ML, Smith AM, Best AR, Wilson DA (2005) High-frequency oscillations are not necessary for simple olfactory discriminations in young rats. J Neurosci 25:792-798.

Friedrich RW (2006) Mechanisms of odor discrimination: neurophysiological and behavioral approaches. Trends Neurosci 29:40-47.

Friedrich RW, Laurent G (2001) Dynamic optimization of odor representations by slow temporal patterning of mitral cell activity. Science 291:889-894.

Giustetto M, Bovolin P, Fasolo A, Bonino M, Cantino D, Sassoe-Pognetto M (1997) Glutamate receptors in the olfactory bulb synaptic circuitry: heterogeneity and synaptic localization of N-methyl-D-aspartate receptor subunit 1 and AMPA receptor subunit 1. Neuroscience 76:787-798.

Hayar A, Karnup S, Ennis M, Shipley MT (2004) External tufted cells: a 
major excitatory element that coordinates glomerular activity. J Neurosci 24:6676-6685.

Heinbockel T, Heyward P, Conquet F, Ennis M (2004) Regulation of main olfactory bulb mitral cell excitability by metabotropic glutamate receptor mGluR1. J Neurophysiol 92:3085-3096.

Hormuzdi SG, Pais I, LeBeau FEN, Towers SK, Rozov A, Buhl EH, Whittington MA, Monyer H (2001) Impaired electrical signaling disrupts gamma frequency oscillations in connexin 36-deficient mice. Neuron 31:487-495.

Huang YH, Sinha SR, Tanaka K, Rothstein JD, Bergles DE (2004) Astrocyte glutamate transporters regulate metabotropic glutamate receptormediated excitation of hippocampal interneurons. J Neurosci 24:4551-4559.

Isaacson JS (1999) Glutamate spillover mediates excitatory transmission in the rat olfactory bulb. Neuron 23:377-384.

Kasowski HJ, Kim H, Greer CA (1999) Compartmental organization of the olfactory bulb glomerulus. J Comp Neurol 407:261-274.

Khan RM, Sobel N (2004) Neural processing at the speed of smell. Neuron 44:744-747.

Kim H, Greer CA (2000) The emergence of compartmental organization in olfactory bulb glomeruli during postnatal development. J Comp Neurol 422:297-311.

Lagier S, Carleton A, Lledo PM (2004) Interplay between local GABAergic interneurons and relay neurons generates gamma oscillations in the rat olfactory bulb. J Neurosci 24:4382-4392.

Laurent G, Wehr M, Davidowitz H (1996) Temporal representations of odors in an olfactory network. J Neurosci 16:3837-3847.

Laurent G, Stopfer M, Friedrich RW, Rabinovich MI, Volkovskii A, Abarbanel HD (2001) Odor encoding as an active, dynamical process: experiments, computation, and theory. Annu Rev Neurosci 24:263-297.

LeMasurier M, Gillespie PG (2005) Hair-cell mechanotransduction and cochlear amplification. Neuron 48:403-415.

Luo M, Katz LC (2001) Response correlation maps of neurons in the mammalian olfactory bulb. Neuron 32:1165-1179.

MacLeod K, Laurent G (1996) Distinct mechanisms for synchronization and temporal patterning of odor-encoding neural assemblies. Science 274:976-979.

Mayer ML, Westbrook GL (1985) The action of N-methyl-D-aspartic acid on mouse spinal neurones in culture. J Physiol (Lond) 361:65-90.

Miller LD, Petrozzino JJ, Connor JA (1995) G-protein-coupled receptors mediate a fast excitatory postsynaptic current in CA3 pyramidal neurons in hippocampal slices. J Neurosci 15:8320-8330.
Montague AA, Greer CA (1999) Differential distribution of ionotropic glutamate receptor subunits in the rat olfactory bulb. J Comp Neurol 405:233-246.

Murphy GJ, Glickfeld LL, Balsen Z, Isaacson JS (2004) Sensory neuron signaling to the brain: properties of transmitter release from olfactory nerve terminals. J Neurosci 24:3023-3030.

Nowycky MC, Mori K, Shepherd GM (1981) Blockade of synaptic inhibition reveals long-lasting synaptic excitation in isolated turtle olfactory bulb. J Neurophysiol 46:649-658.

Rossi DJ, Alford S, Mugnaini E, Slater NT (1995) Properties of transmission at a giant glutamatergic synapse in cerebellum: the mossy fiber-unipolar brush cell synapse. J Neurophysiol 74:24-42.

Salin PA, Lledo PM, Vincent JD, Charpak S (2001) Dendritic glutamate autoreceptors modulate signal processing in rat mitral cells. J Neurophysiol 85:1275-1282.

Schoppa NE, Westbrook GL (2001) Glomerulus-specific synchronization of mitral cells in the olfactory bulb. Neuron 31:639-651.

Schoppa NE, Westbrook GL (2002) AMPA autoreceptors drive correlated spiking in olfactory bulb glomeruli. Nat Neurosci 5:1194-1202.

Schoppa NE, Kinzie JM, Sahara Y, Segerson TP, Westbrook GL (1998) Dendrodendritic inhibition in the olfactory bulb is driven by NMDA receptors. J Neurosci 18:6790-6802.

Sterling P (2004) How retinal circuits optimize the transfer of visual information. In: The visual neurosciences (Chalupa LM, Werner JS, eds), pp 234-250. Cambridge, MA: Bradford Books.

Takeuchi H, Kurahashi T (2005) Mechanism of signal amplification in the olfactory sensory cilia. J Neurosci 25:11084-11091.

Uchida N, Mainen ZF (2003) Speed and accuracy of olfactory discrimination in the rat. Nat Neurosci 6:1224-1229.

Urban NN, Sakmann B (2002) Reciprocal intraglomerular excitation and intra- and interglomerular lateral inhibition between mouse olfactory bulb mitral cells. J Physiol (Lond) 542:355-367.

van den Pol AN (1995) Presynaptic metabotropic glutamate receptors in adult and developing neurons: autoexcitation in the olfactory bulb. J Comp Neurol 359:253-271.

Wilson RI, Turner GC, Laurent G (2004) Transformation of olfactory representations in the Drosophila antennal lobe. Science 303:366-370.

Yuan Q, Knopfel T (2006) Olfactory nerve stimulation-evoked mGluR1 slow potentials, oscillations and calcium signaling in mouse olfactory bulb mitral cells. J Neurophysiol 95:3097-3104. 